\title{
Studies Toward the Total Synthesis of Combretastatin D4
}

\section{Wilson S. Nascimento, ${ }^{\star}$ Walter R. Martinez, Arisson T. Silva, Antônio A. S. Paulino, Paulo H. Menezes and Roberta A. Oliveira}

\author{
Departamento de Química Fundamental, CCEN, UFPE, 50670-901, Recife-PE, Brasil
}

*e-mail:wilsonnascimentolq@hotmail.com

Keywords: combretastatin $D-4$, potassium organotrifluoroborates, macrocyclic lactones

\section{INTRODUCTION}

Compounds isolated from Combretaceae are of great interest and include the bioactive stilbenes and the 17-membered macrocyclic lactones Combretastatins D2 and D4 (Figure 1). ${ }^{1}$<smiles>O=C1CCOCCOc2ccc(cc2O)C1</smiles>

D2

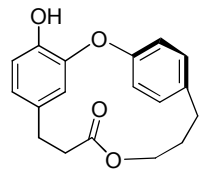

Figure 1. Combretastatines D2 and D4

Different approaches for the synthesis of Combretastatin D2 have been described, but due to date no synthetic approaches as well as cytotoxicity studies have been reported for Combretastatin D4 (CA-D4). The interest in the design and synthesis of angiogenesis inhibitors prompted us to design a new, convergent route to this class of compounds with a view to further studies of biological properties of the natural product and its analogues.

\section{RESULTS AND DISCUSSION}

In our disconnection approach, CA-D4 was divided in two main intermediates, $\mathbf{A}$ and $\mathbf{B}$ (Scheme 1).

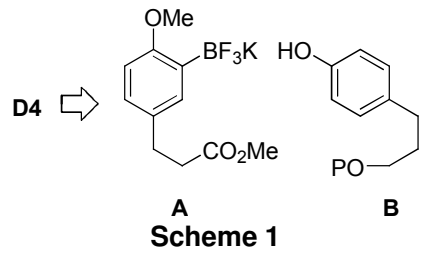

Fragment $A$ was synthesized in $67 \%$ overall yield after three steps (Scheme 2). ${ }^{2}$

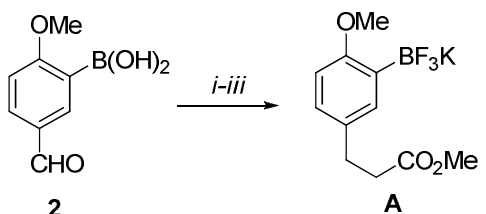

Scheme 2. Reagents and conditions: (i) $\mathrm{KHF}_{2}, \mathrm{MeOH}: \mathrm{H}_{2} \mathrm{O}, 0^{\circ} \mathrm{C}$ 0.5h (90\%); (ii) $\mathrm{Ph}_{3} \mathrm{PCHCO}_{2} \mathrm{Me}, \mathrm{H}_{2} \mathrm{O}, 90^{\circ} \mathrm{C}, 12 \mathrm{~h}$, (86\%); (iii) $\mathrm{H}_{2}$, $\mathrm{Pd} / \mathrm{C}, \mathrm{MeOH}, 12 \mathrm{~h}, 25^{\circ} \mathrm{C}(85 \%)$.

Fragment B was synthesized in four steps from the commercialy available 4 -iodo-phenol in $55 \%$ overall yield (Scheme 3).

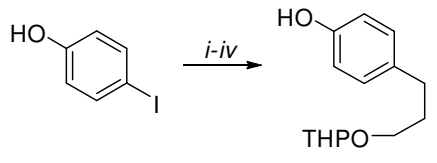

B

Scheme 3. Reagents and conditions: (i) $\mathrm{Ac}_{2} \mathrm{O}, \mathrm{I}_{2}, 5 \mathrm{~h}, 25^{\circ} \mathrm{C}(92 \%)$; (ii) $\mathrm{HC} \equiv \mathrm{CCH}_{2} \mathrm{OTHP}, \mathrm{PdCl}_{2}\left(\mathrm{PPh}_{3}\right)_{2}, \mathrm{Cul}, \mathrm{MeCN} \mathrm{Et}_{3} \mathrm{~N}, 25^{\circ} \mathrm{C}(82 \%)$;

(iii) $\mathrm{NH}_{4} \mathrm{OH}, \mathrm{THF}: \mathrm{MeOH}, 12 \mathrm{~h}, 25^{\circ} \mathrm{C}(80 \%)$; (iv) $\mathrm{H}_{2}, \mathrm{Pd} / \mathrm{C}, \mathrm{MeOH}$, $5 \mathrm{~h}, 25^{\circ} \mathrm{C}(90 \%)$

The obtained fragments were then coupled using an Ullmann type reaction ${ }^{3}$ to yield an advanced intermediate in the synthesis of the target molecule (Scheme 4).

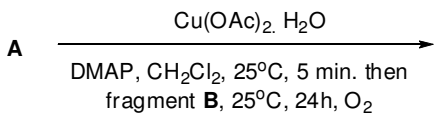
fragment $\mathrm{B}, 25^{\circ} \mathrm{C}, 24 \mathrm{~h}, \mathrm{O}_{2}$

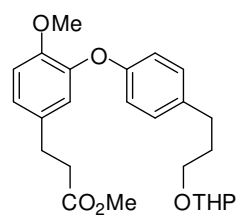

$65 \%$

Scheme 4

\section{CONCLUSION}

In summary, an advanced intermediate in the synthesis of CA-D4 was achieved. The synthesis features the use of a potassium aryltrifluoroborate as a synthon and using this approach, all carbon atoms present in the structure were installed Further progress toward the synthesis will be reported in the due course.

\section{ACKNOWLEDGEMENTS}

The authors gratefully acknowledge CNPq, CAPES, FACEPE and INCT-INAMI for the financial support.

\section{REFERENCES}

${ }^{1}$ Cirla, A.; Mann, J. Nat. Prod. Rep., 2003, 20, 558-564.

${ }^{2}$ Oliveira, R. A.; Molander G. A. Tetrahedron Lett. 2008, 49, 1266-1268.

${ }^{3}$ Quach, T. D.; Batey, R.A. Org. Lett. 2003, 5, 1381-1384.

$14^{\text {th }}$ Brazilian Meeting on Organic Synthesis $-14^{\text {th }}$ BMOS - September 01-05, 2011-Brasilia, Brazil 